\title{
Role of Some Fatty Acids in the Dynamics of Follicular Fluid in She- Camel
}

Ghada M. Nabil, A.E. Abdel Ghaffar* and M.E.A. Abou El. Roos*, Biochemistry Department,National Research Center, Cairo, and ${ }^{*}$ Theriogenology Department, Fac. Vet. Med (Moshtohor), Toukh, Benha, Egypt.

\begin{abstract}
7 HE MAIN objective of this work was to determine the activity of some antioxidants and content of fatty acid in the follicular fluid in relation to size of the follicle and quality of oocyte in she camels (Camelus dromedaries). The vesicular follicles ( $\geq 3 \mathrm{~mm}$ in diameter) were selected from the obtained ovaries, and classified according to their surface diameter into small, medium, large and very large size follicles $(3-5,>5-10,>10-15$ and $>15 \mathrm{~mm}$, respectively). The aspirated follicular fluid was centrifuged to separate cell fraction and then examined for oocyte quality. Most of the recovered small and medium size follicles were of good quality (69.23 and 59.19\%, respectively) in comparison to those recovered from large and very large ones (33.33 and $23.08 \%$, respectively ). The activity of SOD (superoxide dismutase) was elevated and those of GSH (glutathione) dropped in the follicular fluid as the diameter of follicles increased and the percentage of oocytes with good quality was decreased. Palmitic (C16:0) and oleic (C18:1) acids were the most abundant fatty acids in the follicular fluid, while, those of stearic (C18:0), linoleic (C18:2) and arachidonic (C20:4) acids were lower. Other fatty acids were very low. Moreover, the content of stearic (C18:0), oleic (C18:1), linoleum (C18:2) and arachidonic (C20:4) acids in the follicular fluid declined as the diameter of follicles was increased and the percentage of oocytes with good quality decreased. Those of other fatty acids did not vary significantly with the change in the size of follicle and /or quality of oocytes.
\end{abstract}

Keywords: Follicular fluid, Oocytes, Fatty acids.

The $\mathrm{Na}^{+} \mathrm{K}^{+}$-ATPase (sodium pump) is a member of the $\mathrm{P}_{2}$-type ATPase family, which includes gastric $\mathrm{H}^{+} \mathrm{K}^{+}$-ATPase and sarcoplasmic reticulum $\mathrm{Ca}^{2+}$. ATPase $^{(1)}$. The Na,K-ATPase is a heterodimeric membrane protein that pumps 3 $\mathrm{Na}^{+}$ions out- and $2 \mathrm{~K}^{+}$ions into the cell, at the expenditure of the energy derived from hydrolysis of one ATP molecule. Consequently Na,K-ATPase establishes an electrochemical gradient for these ions across the plasma membrane, which is indispensible for many cell functions. The enzyme consists of a catalytic $\alpha$ subunit that undergoes ions- and ATP-dependent conformational transitions coupling ATP hydrolysis to ion transport, and a glycosylated $\beta$-subunit that is important for function, folding, and plasma membrane delivery of the overall enzyme complex ${ }^{(2)}$. The sodium pump also contains a highly conserved site of inhibition by cardiac glycosides, which represents the molecular basis for the use of these drugs in the treatment of congestive heart failure. Significantly, the 
cardiac glycoside binding site on the Na,K-ATPase has been shown to be important in blood pressure regulation ${ }^{(3)}$

It was found natural modulators of P-type pumps in plants.In this direction, Oleic $\left(\mathrm{C}^{18}: 1\right.$, cis $\left.-\Delta^{9}\right)$ and linoleic $\left(\right.$ cis, cis $\left.-\Delta^{9}, \Delta^{12}\right)$ acids are abundantly present in several healthy plant oils. Indeed, the levels of predominantly these two fatty acids have been shown to build up in the plasma of animals challenged with high salt intake ${ }^{(4)}$. Additionally, oleic acids have unambiguously been shown to have a blood pressure lowering effect ${ }^{(5)}$. The above considerations motivated us to perform detailed analysis to compare the effect of fatty acids on pump mechanism.

The in vitro production of she camel embryos received interest in recent years $^{(6,7)}$. For reaching successful embryo transfer programs, a clear understanding of some factors that affect growth, maturation and development of follicles and oocytes is necessary ${ }^{(8)}$. The ability of she camel oocyte to mature in vitro depends on the presence or absence of cumulus cells ${ }^{(9)}$; ovarian activity ${ }^{(10)}$ and intra follicular environment ${ }^{(11)}$. However, the development competence of oocytes for in vitro fertilization depends upon the rate of follicular growth ${ }^{(12)}$. A new approach to investigate the contribution of metabolic adaptations to the pathogenesis of reduced fertility is to mimic biochemical changes in an in vitro model so as to study their effects on in vitro granulosa cell function ${ }^{(13)}$, oocyte maturation, fertilization and subsequent embryo yield ${ }^{(14)}$. The follicular microenvironment is involved in regulating a critical transition in late follicular development and the selection of dominant follicle ${ }^{(15)}$. The oocyte development is a tightly regulated by a balance between the circulating hormones and the local intra-ovarian steroidal and non-steroidal factors ${ }^{(16)}$. The follicular fluid in which the oocyte is bathed has many substances produced by granulosa and theca cells and a transudate serum components transported through the blood follicle barriers $^{(17)}$. It contains steroid hormones ${ }^{(18-20)}$, growth factors, cytokines, free radicals and antioxidant ${ }^{(21,22)}$. The antioxidant activities in the ovarian follicles change in a similar manner to serum steroid content ${ }^{(23)}$. Moreover, the polyunsaturated fatty acids are essential to gamete fertility ${ }^{(24)}$. The oocyte selection for in vitro maturation and cryopreservation tolerance of immature oocytes may eventually be evaluated by analysis of fatty acid composition ${ }^{(25)}$.

The aim of the current investigation was to measure quantitatively the activities of SOD and GSH quantitativily and level of fatty acid in the follicular fluid of ovarian follicles with variable sizes and their relation to oocyte quality in she camels (Camelus dromedarius).

\section{Materials and Methods}

The ovaries were collected during March and April from 56 non pregnant one humped she camels (Camelus dromedarius) slaughtered in Belbiase and Cairo Abattoirs. The slaughtered she camels had not available reproductive history. The age of animals ranged between 4 to 12 years. Immediately after slaughtering both ovaries were collected from each female and kept in normal

Egypt. J. Biophys. Biomed. Engng. Vol. 12 (2011) 
physiological saline $(0.9 \% \mathrm{NaCl})$, then transported within $60-120$ min to the laboratory in a container containing ice bags $\left(4^{\circ} \mathrm{C}\right)$. In the laboratory, the ovaries were washed in phosphate buffer saline and examined macroscopically especially for the size of ovarian follicles, which were measured using a special caliber. The follicles were classified according to their surface diameter into four groups: small $(3-5 \mathrm{~mm})$; medium $(>5-10 \mathrm{~mm})$; large $(>10-15 \mathrm{~mm})$ and very large $(>15 \mathrm{~mm})$. All the selected follicles were aspirated using 22-gauge needle attached to a syringe. The aspirated follicular fluid was centrifuged at $4{ }^{\circ} \mathrm{C}$ (400 $\mathrm{g} / 5 \mathrm{~min}$ ) in order to separate the fluid from cells. The retrieved cumulus- oocyte complex (COC) was picked up and examined under stero-microscope. Those oocytes were classified as good or poor. The good quality oocyte, displaying compact multilayered corona radiata, homologus arrangement of cumulus oophorus, light and transparent aspect of zona pellucida investment, and an ooplasm with homogenously dispersed pigment. The bad quality oocytes displayed a heterogeneous arrangement of follicular cells and irregular ooplasm with pigment spots. Moreover, after separation of the fluid from cell fraction, the follicular fluid of two small surface diameter follicles with good or with poor oocyte quality was pooled separately to obtain sufficient volume for running assays. The follicular fluid of each size group was further recentrifuged at $4^{\circ} \mathrm{C}$ $(3000 \mathrm{~g} / 10 \mathrm{~min})$, and then stored at $-20^{\circ} \mathrm{C}$ until analysed.

In each sample of the follicular fluid, the total protein content was estimated ${ }^{(26)}$ and the activities of total $\mathrm{SOD}^{(27)}$ and $\mathrm{GSH}^{(28)}$ were determined. The total SOD activity was expressed as $\mathrm{ng} / \mathrm{mg}$ protein meanwhile, those of GSH was recorded as $\mu \mathrm{g} / \mathrm{mg}$ protein. The content of fatty acid was assayed using gas liquid chromatography ${ }^{(29)}$. Data obtained were statistically analyzed using Statistical Analysis System (SAS) $)^{(30)}$.

\section{Results}

The obtained results are presented in Tables 1, 2 and 3.Where Table 1 shows the relation between quality of oocytes recovered from ovarian follicles, as follicular size , number of follicles and oocyte quality.

TABLE 1. Quality of oocytes recovered from ovarian follicles.

\begin{tabular}{|l|c|c|c|c|c|}
\hline \multirow{2}{*}{$\begin{array}{c}\text { Follicular surface } \\
\text { diametrer(mm) }\end{array}$} & \multirow{2}{*}{$\begin{array}{c}\text { Number } \\
\text { of }\end{array}$} & \multicolumn{5}{|c|}{ Oocyte quality } \\
\cline { 3 - 6 } & follicles & $\mathbf{n}$ & \% & $\mathbf{n}$ & Poor \\
\cline { 3 - 6 } & 52 & 36 & 69.23 & 16 & 30.77 \\
\hline Small (3-5) & 22 & 13 & 59.19 & 9 & 40.91 \\
\hline Medium (>5-10) & 15 & 5 & 33.33 & 10 & 66.67 \\
\hline Large (>10-15) & 13 & 3 & 23.08 & 10 & 76.92 \\
\hline Very Large (>15) & & \multicolumn{5}{|c|}{} \\
\hline
\end{tabular}

Table 2 shows the relation between activities of SOD and GSH in the follicular fluid and their relation to surface diameter of follicle and quality of oocyte. Follicular size in millimeter, number of follicles and type of antioxidant ( SOD and GSH). 
TABLE 2. Activities of SOD and GSH in the follicular fluid and their relation to surface diameter of follicle and quality of oocyte.

\begin{tabular}{|c|c|c|c|}
\hline \multirow{2}{*}{$\begin{array}{c}\text { Follicular surface } \\
\text { diameter } \\
(\mathbf{m m})\end{array}$} & \multirow[t]{2}{*}{$\mathbf{n}$} & \multicolumn{2}{|c|}{ Type of antioxidant } \\
\hline & & $\begin{array}{c}\text { SOD } \\
(\mathbf{n g} / \mathrm{mg} \text { protein })^{2}\end{array}$ & $\begin{array}{c}\text { GSH } \\
(\mu g / \text { g protein })^{2}\end{array}$ \\
\hline \multicolumn{4}{|l|}{ Small (3-5) } \\
\hline With good oocyte & 18 & $1.53 \pm 0.29^{\mathrm{c}}$ & $12.14 \pm 1.06^{\mathrm{a}}$ \\
\hline With poor oocyte & 8 & $4.14 \pm 0.71^{b}$ & $6.77 \pm 0.99^{c}$ \\
\hline Overall & 26 & $2.33 \pm 0.37^{\mathrm{C}}$ & $10.49 \pm 0.92^{\mathrm{A}}$ \\
\hline \multicolumn{4}{|l|}{ Medium (>5-10) } \\
\hline With good oocyte & 13 & $2.32 \pm 0.29^{c}$ & $10.87 \pm 1.17^{\mathrm{ab}}$ \\
\hline With poor oocyte & 9 & $5.55 \pm 0.52^{b}$ & $7.53 \pm 1.12^{c}$ \\
\hline Overall & 22 & $3.64 \pm 0.43^{\mathrm{B}}$ & $9.50 \pm 0.90^{\mathrm{A}}$ \\
\hline \multicolumn{4}{|l|}{ Large $(>10-15)$} \\
\hline With good oocyte & 5 & $4.42 \pm 0.75^{b}$ & $7.82 \pm 1.10^{\mathrm{bc}}$ \\
\hline With poor oocyte & 10 & $6.56 \pm 1.10^{\mathrm{ab}}$ & $5.51 \pm 0.74^{\mathrm{c}}$ \\
\hline Overall & 15 & $5.85 \pm 0.81^{\mathrm{A}}$ & $6.28 \pm 0.67^{\mathrm{B}}$ \\
\hline \multicolumn{4}{|l|}{ Very Large $(>15)$} \\
\hline With good oocyte & 3 & $5.62 \pm 0.84^{b}$ & $6.93 \pm 1.16^{\mathrm{b}}$ \\
\hline With poor oocyte & 10 & $8.37 \pm 0.98^{\mathrm{a}}$ & $5.46 \pm 0.66^{\mathrm{c}}$ \\
\hline Overall & 13 & $7.73 \pm 0.84^{\mathrm{A}}$ & $5.80 \pm 0.58^{\mathrm{B}}$ \\
\hline \multicolumn{4}{|l|}{ Total } \\
\hline With good oocyte & 39 & $2.48 \pm 0.28^{I I}$ & $10.76 \pm 0.70^{1}$ \\
\hline With poor oocyte & 37 & $6.28 \pm 0.51^{1}$ & $6.26 \pm 0.45^{\mathrm{II}}$ \\
\hline Overall & 76 & $4.33 \pm 0.36$ & $8.57 \pm 0.50$ \\
\hline
\end{tabular}

Means with different small or capital alphabetical or Latin number superscripts in each vertical column are significantly different $(\mathrm{p}<0.05)$.

Table 3. shows the relation between fatty acids content in the follicular fluid and their relation to surface diameter of follicle and quality of oocyte.

\section{Discussion}

We have provided evidence that an increase in the level of oleic and linoleic acids in the membrane locks the sodium pump in a potassium-free $\mathrm{E}_{2} \mathrm{P}$ conformation, the form that binds cardiac glycosides with high affinity. Indeed, the unsaturation at $\mathrm{C}^{9}$ in oleic acid seems to be important in shifting ouabain affinity, and further unsaturation at $C^{12}$ (linoleic acid) or at $C^{12}$ and $C^{15}$ (linolenic acid) reduces the shift. Hence, the sodium pump may be a player in the oleic acid sustained blood pressure decrease ${ }^{(31)}$.

Under the current investigation, the percentage of oocyte with good quality gradually decreased as the follicular surface diameter was increased (Table 1). These results were in accordance with that mentioned previously ${ }^{(22,32)}$. They recorded the possible effects of follicular surface diameter and intrafollicular environment on variability of developmental capacity and quality of oocytes.

Egypt. J. Biophys. Biomed. Engng. Vol. 12 (2011) 


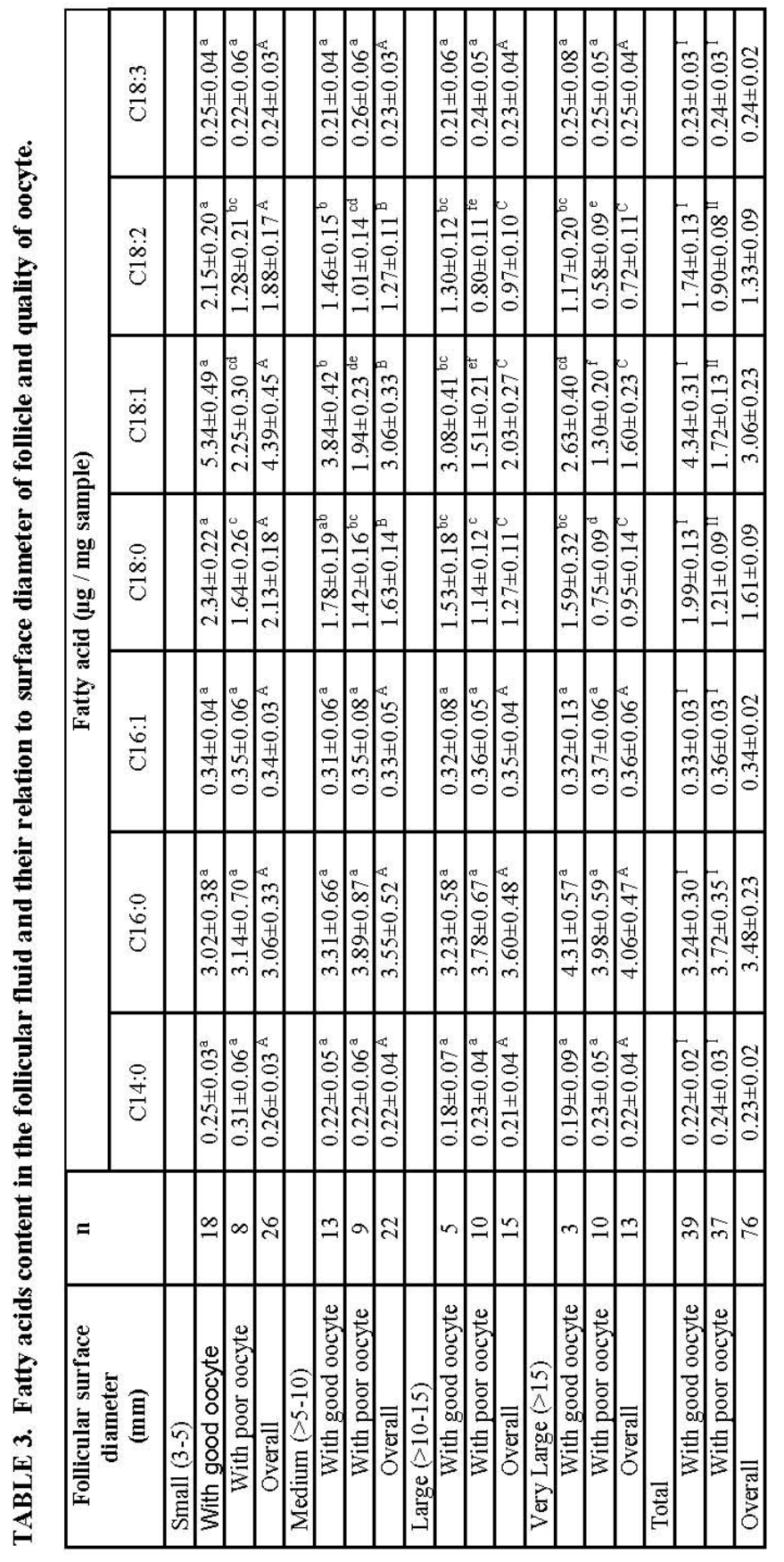


GHADA M. NABIL et al.

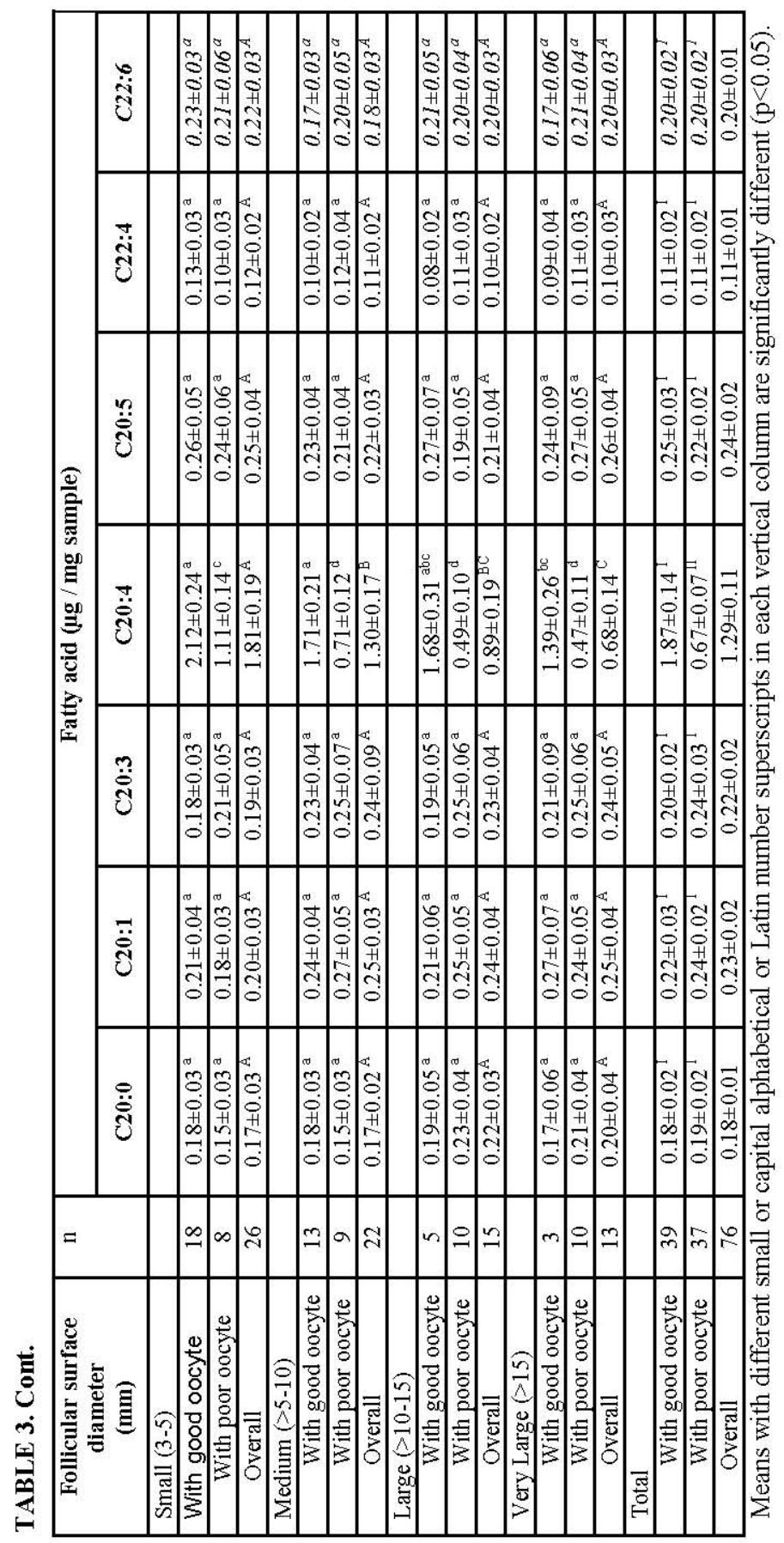

Egypt. J. Biophys. Biomed. Engng. Vol. 12 (2011) 
The present work revealed that the activities of some antioxidant and content of fatty acid in the follicular fluid of she camels are subjects to marked changes according to the surface diameter of follicle and quality of oocyte. Concomitantly, the activities of SOD in the follicular fluid were significantly elevated as the diameter of follicle was increased and percentage of oocyte with good quality was decreased (Table 2). This observation coincides with the previous finding of EL-Din Zain \& Omar ${ }^{(22)}$. Moreover, the decline in percentage of oocytes with good quality as the SOD level was increased may be due to the protection against reactive oxygen species (ROS) ${ }^{(33)}$.

In the present study, the activities of GSH in follicular fluid of she camels significantly dropped with the increase in diameter of follicle and decrease in percentage of oocytes with good quality (Table 2). This finding came in consistent with previous reports ${ }^{(22)}$. However, the high level of GSH in follicular fluid of good quality oocytes may be due to coupling between these cells and oocyte via heterogolous junctions which is critical for oocyte maturation ${ }^{(34)}$.

In general, the results of this work provide the first detailed data on the change of fatty acid composition in follicular fluid of she camels. The concentration of palmitic (C16:0) and oleic (C18:1) acids were the most abundant fatty acids in the follicular fluid, while, those of stearic (C18: 0), linoleic (C18:2) and arachidonic (C20:4) acids were somewhat lower and those of other fatty acids were low (Table 3$)$. However, the palmitic (C16:0), stearic $(\mathrm{C} 18: 0)$ and oleic $(\mathrm{C} 18: 1)$ acids were the first, second and third most abundant fatty acids in oocytes, respectively ${ }^{(35,25)}$. The myristic acid (C14: 0$)$ consider the most abundant fatty acid in embryo ${ }^{(36)}$. They attributed the difference in fatty acid composition to species, breed and age differences. Regarding to the effect of the surface diameter of follicle and / or quality of oocyte on the fatty acid composition in the follicular fluid of she camel, the present data revealed a significant reduction in the contents of stearic (C18:0), oleic (C18:1), linoleic (C18:2) and arachidonic (C20:4) acids in the follicular fluid as the diameter of follicle was increased and the percentage of oocytes with good quality was decreased, meanwhile, those of other fatty acids did not varied significantly with the change in size of follicle and /or quality of oocyte (Table, 3 ). In this respect, the fatty acid content may be important for oocyte competence and for differences in fertilization and developmental potential ${ }^{(25)}$. Indeed, the palmitic (C16: 0) and oleic (C18:1) acids were required as substrates for fatty acids elongation and desaturation ${ }^{(37)}$. The linoleic acid in the follicular fluid may be important in regulating meiotic arrest of oocytes at the germinal vesicle stage ${ }^{(38)}$. Arrachidonic (C20:4) acid can be synthesized from linoleic (C18:2) acid, and oocytes may benefit by storing the more versatile precursor preferentially, which is at lower risk of free radical damage ${ }^{(35)}$. Additionally, oleic (C18:1), linoleic (C18:2) and arachidonic (C20:4) acids appeared more elevated in oocytes with high grade, than those with low grade ${ }^{(25)}$.

In conclusion, the selection of good oocytes for in vitro maturation and fertilization in she camels may eventually be based on the surface diameter of 
ovarian follicles. Other diagnostic methods for dynamics of follicular fluid include detailed knowledge of the micro-environment of oocyte particularly the activities of SOD and GSH, in addition to the content of stearic (C18:0), oleic (C18:1), linoleic (C18:2) and arachidonic (C20:4) acids may be used as a tool for predicting the good quality oocyte. It also gives a better understanding of the complexity of events controlling the follicular requirements for growth, maturation and maintenance of viability of oocytes in she camels.

\section{References}

1. Kühlbrandt, W. P-type ATPases. Nat. Rev. 5, 282-295 (2004).

2. Kaplan, J.H. Na,K-ATPase. Ann. Rev. Biochem. 71, 511-535 (2002).

3. Dostanic-Larson, I. Van Huysse, J.W. Lorenz, J.N. and Lingrel, J.B. The highly conserved cardiac glycoside binding site of $\mathrm{Na}, \mathrm{K}$-ATPase plays a role in blood pressure regulation, Proc Natl Acad Sci. USA 102, 15845-15850 (2005).

4. Tamura, M. Kuwano, H. Kinoshita, T. and Inagami, T., Identification of linoleic and oleic acids as endogenous $\mathrm{Na}^{+}, \mathrm{K}^{+}$-ATPase inhibitors from acute volume-expanded Hog plasma, J Biol. Chem. 260, 9672-9677 (1985).

5. Terés, S. Barceló-Coblijn, G. Benet, M. Álvarez, R. Bressani, R. and Halver, J.E. Escribá, Oleic acid content is responsible for the reduction in blood pressure induced by olive oil, Proc. Natl. Acad. Sci. USA, 105,13811-13816 (2008).

6. Delcampo, M.R., Delcampo, C.H., Adams, G.P. and Mapletoft, R.J. The application of new reproductive technologies to South American Camelids. Theriogenology, 43, 21-30 (1995).

7. Tibary , A. and Anouassi, A. "Theriogenology in Camelidae" : Abu Dhabi Printing Press, Mina Abu Dhabi, United Arab Emirates . pp: 447 (1997).

8. Albertini, D., Catherine, M., Combelles, H., Benecch, E. and Carabatsos, M.J. Cellular basis for paracrine regulation of ovarian follicle development. Reproduction, 121, 647-653 (2001).

9. Ghoneim, I.M., Torner , H., Heleil, B., Srsen , V., Fattouh, E.M. and AIm, H. In vitro maturation of cumulus oocyte complexes of pregnant and non pregnant Camelus dromedarius. Journal of Egyptian Veterinary Medicine Association, 59, 1649-1659 (1999).

10. Hagemann, L.J. Influence of the dominant follicles on oocytes from subordinate follicles. Theriogenology 51, 445-459 (1999).

11. Testart, J. Criteria for evaluating the quality of oocytes and their aptitude for IVE . Annales de Biologie Clinique (Paris), 43, 17-21 (1985)

12. Trounson, A., Anderiesz, C. and Jones, G. Maturation of human oocytes in vitro and their developmental competence. Reproduction, 121, 51-75 (2001).

Egypt. J. Biophys. Biomed. Engng. Vol. 12 (2011) 
13. Vanholder, T., Opsomer G., Van Soon A., Coryn M. and de Kruif A. Effect of oleic acid on oestradiol - $17 \beta$ production of bovine granulosa cell. Reproduction of Domestic Animal, 38, 346 - 347 (2003).

14. Leroy, J.L.M.R., Vanholder, T., Van Soon A., Opsommer, G., Bols, P. and de Kruif, A. Effect of oleic acid during in vitro maturation on fertilization, first cleavage and embryo development of bovine cumulus - oocyte - complexes. Reproduction of Domestic Animal, 38, 328 (2003).

15. Fortune, J.E., Rivera, G.M. and Yang, M.Y. Follicular development: The role of follicular micro- environment in selection of dominant follicle. Animal Reproduction Science. 82-83,109-126 (2004).

16. Yang, X., Kubota, C., Suzuki, H., Taneja, M., Bols, P.E.J. and Presicce, G.A. Control of oocyte maturation in cows. Biological factors. Theriogenolgy, 49, 471-482 (1998)

17. Edwards, R.G. Follicular fluid. Journal of Reproduction and Fertility, 37,189-219 (1974).

18. Abdel Ghaffar, A.E., Ragab Omaima A. and El-Gaafary, M.N. Some enzymatic and hormonal studies on the fluid of normal and atretic follicles in the ovaries of she camels. Zagazig Veterinary. Journal, 23(3):120-130 (1995).

19. Basiouni, G.F. Ovarian steroid concentrations and follicle development in the female camel (Camelus dromedarius). Pakistan Veterinary Journal, 17 (2), 79-81 (1997)

20. Salem, H.A.H., Serur, B.H. and Amer, H.A. Oestradiol, progesterone and thyroxine in follicular fluid of normal, cystic and atretic follicles of non pregnant camels in Saudi Arabia. Journal of Camel Practice and Research, 4 (1), 81-83 (1997)

21. Attaran, M., Pasqualotto, E., Falcone, T., Goldberg, J.M., Miller, K.F., Agarwal, A. and Sharama , R.k. The effect of follicular fluid reactive oxygen species on outcome of in vitro fertilization. International Journal of Fertility, 45(5), 314-320 (2000).

22. El-Din Zain, A. and Omar, H.M. Some antioxidants activities, lipid peroxide and nitric oxide levels in the follicular fluid and its relation to oocyte quality in buffalo cows. Assiut Veterinary Medicine Journal, 49 (96), 293-310 (2003).

23. Doyle, M.B., Prestoin, S.L., Gatzuili, E. and Behrman, H.R. Oxygen radicals antioxidants in follicular fluid and oocyte function. (Abstract No. 123), Society Gynecology Investigation (1990).

24. Nissen, H.P. and Kreysel, H.W. Polyunsaturated fatty acids in relation to sperm motility. Andrologia, 15, 264-269 (1983).

25. Kim, J.Y., Kinoshita, M., Ohnishi, M. and Fukui, Y. Lipid and fatty acid analysis of fresh frozen-thawed immature and in vitro matured bovine oocytes. Reproduction, 122, 131-138 (2001). 
26. Lowery, O.H., Rosebrough, N.J., Farr, A.L. and Randall, R.J. Protein measurement with the folin phenol reagents. Journal of Biological Chemistry, 139, 265-275 (1951).

27. Misra, H.P. and Fridovich, I. The role of superoxide anion in the antioxidants of epinephrine and a simple assay for superoxide dismutase. Journal of Biological Chemistry, 247, 3170-3175 (1972)

28. Beutler , E., Duron , O. and Kelly , B. M. Improved method for the determination of blood glutathione. Journal of Laboratory Clinical Medicine, 61, 882-888 (1963)

29. Nawrocki, A. and Gorski, J. Effect of plasma free fatty acid concentration on the content and composition of the free fatty acid fraction in rat skeletal muscles. Hormonal Metabolism Research, 36 (9), 601-606 (2004)

30. Statistical Analysis System (SAS) User's North Carolina (1987).

31. Mahmmoud, Y. A. and Christensen, S. B. Oleic and linoleic acids are active principles in Nigella sativa and stabilize an $\mathrm{E}_{2} \mathrm{P}$ conformation of the $\mathrm{Na}, \mathrm{K}-\mathrm{ATPase}$. Fatty acids differentially regulate cardiac glycoside interaction with the pump, Biochim. Biophys. Acta, 1808, 2413-2420 (2011).

32. Hazeleger, N.L., Hill, D.J., Stubbings, R.B. and Walton, J.S. Relationship of morphology and follicular fluid environment of bovine oocytes to their development potential in vitro. Theriogenology, 43, 509-522 (1995)

33. Halliwell, B. Free radicals and antioxidants: A personal View. Nutrition Review, 52, 253-265 (1994).

34. de - Matos , D.G., Furnus , C.C. and de Matos , D.F. Glutathione synthesis during in vitro maturation of bovine oocytes : Role of cumulus cells. Biology of Reproduction. 57,1420-1425 ( 1997).

35. McEvoy, T.C., Coull, G.D., Broadbent, P.J., Hutehinson, J.S.M. and Speak, B.K. Fatty acid composition of lipids in immature cattle, pig and sheep oocyte with intact zona pellucida. Journal of Reproduction and Fertility, 118, 163-170 (2000)

36. Sata, R., Tsujii, H., Abe, H., Yamashita, S. and Hoshi, H. Fatty acid composition of bovine embryos cultured in serum free and serum containing medium during early embryonic development. Journal of Reproduction Development, 45, 97-103 (1999).

37. Jaffcoat The biosynthesis of unsaturated fatty acids and its control in mammalian liver. Essays in Biochemistry, 15,1-36 (1979).

38. Homa, S.T. and Brown, C.A. Changes in linoleic acid during follicular development and inhibition of spontaneous breakdown of germinal vesicles in cumulus free bovine oocytes. Journal of Reproduction and Fertility, 94,153-160 (1992). 


\section{دور بعض الأحماض الدهنية في ديناميكية السائل الجريبي في النوق}

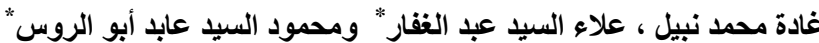

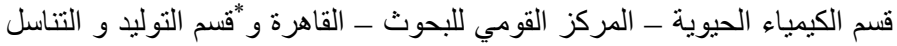

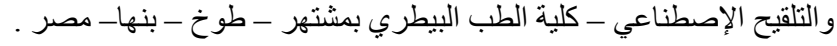

الهذف الأساسي لهذا العمل هو تحديد أنشطة بعض مضادات الأكسدة و تركيز

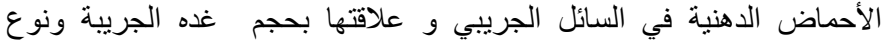

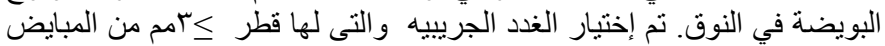

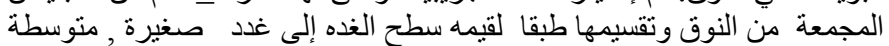
, كبيرة و كبيرة جدا في القطر (r- 0ـ , >

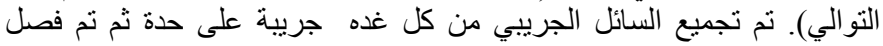

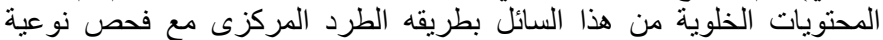

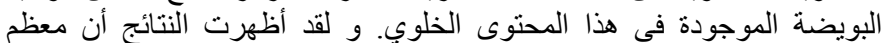

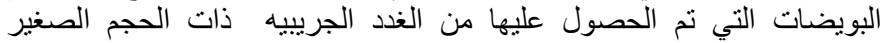

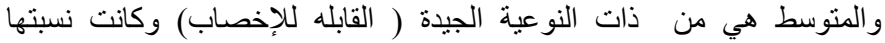

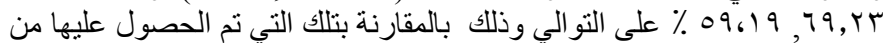

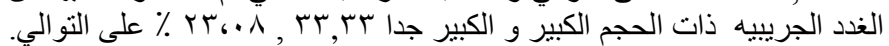

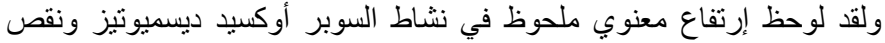

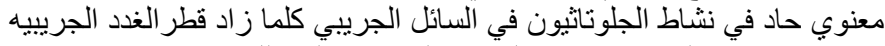

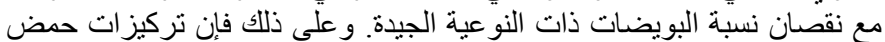

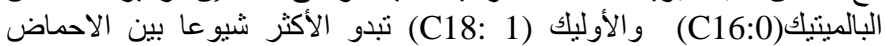

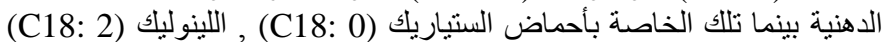

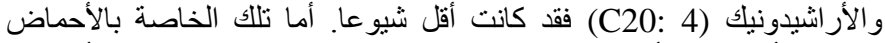

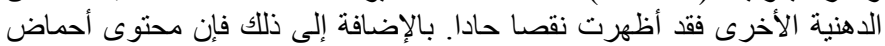

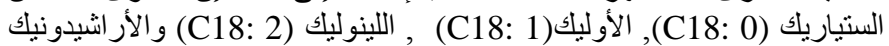

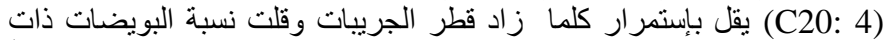

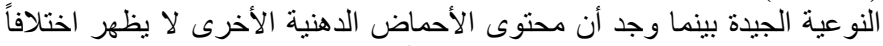

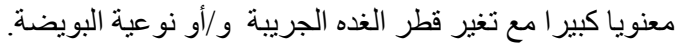

